\title{
The Impacts of Deep Surgical Site Infections on Readmissions, Length of Stay, and Costs: A Matched Case-Control Study Conducted in an Academic Hospital in the Netherlands
}

This article was published in the following Dove Press journal:

Infection and Drug Resistance

\begin{abstract}
Abdul Khairul Rizki Purba $\mathbb{D}^{1-4}$
Christian F Luz $\mathbb{D D}^{2}$

Riyanti R Wulandari ${ }^{5}$

leneke van der Gun ${(\mathbb{D})^{2}}^{2}$

Jan-Willem Dik $\mathbb{D}^{2}$

Alex W Friedrich (D) $^{2}$

Maarten J Postma ${ }^{1,3,4,6}$

'Department of Health Sciences, University of Groningen, University Medical Center Groningen, Groningen, the Netherlands; ${ }^{2}$ University of Groningen, University Medical Center Groningen, Department of Medical Microbiology, Groningen, the Netherlands; ${ }^{3}$ Department of Pharmacology and Therapy, Faculty of Medicine, Universitas Airlangga, Surabaya, Indonesia; ${ }^{4}$ Unit of Pharmacotherapy, -Epidemiology and -Economics (PTE2), Department of Pharmacy, Faculty of Science and Engineering, University of Groningen, Groningen, the Netherlands; ${ }^{5}$ Department of Pharmacy, Dinas Kesehatan Kota Surabaya, Surabaya, Indonesia; ${ }^{6}$ Department of Economics, Econometrics and Finance, Faculty of Economics \& Business, University of Groningen, Groningen, the Netherlands
\end{abstract}

Correspondence: Abdul Khairul Rizki Purba

Universitair Medisch Centrum Groningen, Hanzeplein I, Groningen 9700RB, the Netherlands,

Tel +6281230019201

Email khairul_purba@fk.unair.ac.id
Objective: This study aimed to evaluate the impacts of deep surgical site infections (dSSIs) regarding hospital readmissions, prolonged length of stay $(\mathrm{LoS})$, and estimated costs.

Patients and Methods: We designed and applied a matched case-control observational study using the electronic health records at the University Medical Center Groningen in the Netherlands. We compared patients with dSSI and non-SSI, matched on the basis of having similar procedures. A prevailing topology of surgeries categorized as clean, clean-contaminated, contaminated, and dirty was applied.

Results: Out of a total of 12,285 patients, 393 dSSI were identified as cases, and 2864 patients without SSIs were selected as controls. A total of 343 dSSI patients (87\%) and $2307(81 \%)$ controls required hospital readmissions. The median LoS was 7 days $\left(\mathrm{P}_{25}-\mathrm{P}_{75}: 2.5-14.5\right)$ for dSSI patients and 5 days $\left(\mathrm{P}_{25}-\mathrm{P}_{75}: 1-9\right)$ for controls ( $p$-value: $\left.<0.001\right)$. The estimated mean cost per hospital admission was $€ 9,016$ ( $\mathrm{SE} \pm 343$ ) for dSSI patients and $€ 5,409$ ( $\mathrm{SE} \pm 120$ ) for controls $(p<0.001)$. Independent variables associated with dSSI were patient's age $\geq 65$ years (OR: 1.334; 95\% CI: $1.036-1.720$ ), the use of prophylactic antibiotics (OR: $0.424 ; 95 \%$ CI: $0.344-0.537$ ), and neoplasms (OR: 2.050; 95\% CI: 1.473-2.854).

Conclusion: dSSI is associated with increased costs, prolonged LoS, and increased readmission rates. Elevated risks were seen for elderly patients and those with neoplasms. Additionally, a protective effect of prophylactic antibiotics was found.

Keywords: surgical wound infection, prophylactic antibiotic, patient admission, economic evaluation, cost

\section{Introduction}

Surgical site infections (SSIs) present a high risk of prolonged lengths of stay (LoS) and readmissions. ${ }^{1-5}$ In the United States, SSIs reportedly occurred in $1.9 \%$ of surgical procedures. ${ }^{6}$ These infections incur costs, ranging between US\$480 and US\$22,130 per patient. ${ }^{7}$ In addition, the European Centre for Disease Prevention and Control (ECDC) in 2011-2012 reported that SSI was the most common healthcare-associated infection with an incidence of 156.5 per 100,000 population. ${ }^{8}$ Most concern exists about specific sites of infections, such as deep SSI (dSSI) involving infection of soft tissues of fascia and muscles with a high risk of development of sepsis as a complication. ${ }^{1,9}$ In addition, a correlation has been found between the type of surgery, categorized according to the prevailing typology of clean, clean-contaminated, 
contaminated and dirty surgeries, and the risk of contracting an SSI. ${ }^{10-12}$ Operation procedures with clean-contaminated and dirty have been reported being associated with a high burden of dSSI. ${ }^{13-15}$

Among European countries, the Netherlands has implemented an integrative stewardship program that has been effectively performed in many Dutch hospitals to manage hospital infections including dSSI. The program is applied for antimicrobial use, infection prevention, and diagnostic stewardship, involving a multidisciplinary team with infectious diseases, infection control practitioners as well as clinical microbiologists and hospital pharmacists. ${ }^{16,17}$ From the ECDC 2016 and 2017 reports, SSI incidence in the Netherlands is shown to have decreased from 2.2 to 1.0 per 100 surgeries, respectively. ${ }^{8}$ In general, the burden of healthcare-associated infections on the European population has been estimated at 501 disability-adjusted life years (DALYs) per 100,000 general population annually. ${ }^{8}$ In the Netherlands, dSSI was responsible for 3200 DALYs per year for colectomies and 1200 DALYs per year for total hip arthroplasties, with the national financial burdens for each of these conditions estimated at $€ 29$ million and $€ 10$ million, respectively. ${ }^{18}$

A dSSI surveillance performed for the Netherlands ("PREZIES"; 1996-2004), documented dSSI rates at 3.7\% in 93,511 surgical procedures, with the highest dSSI rate in the procedures of colon resections (6.7\%). ${ }^{19,20}$ An evidence found that in contrast to superficial SSIs, dSSIs contribute an additional mean LoS of 2-2.6 days. ${ }^{21} \mathrm{dSSIs}$ are considered a high burden in the group of hospitalization infection. ${ }^{21,22}$ To deal with the burden of dSSI, various modalities have been implemented, ranging from the use of prophylactic antibiotics before surgical incision to the subsequent antibiotic treatment of dSSI, including empiric treatment that being installed based on national/local guidelines. ${ }^{23,24}$ In the practical setting of the implementation of the strategies, it is important to assess the impacts of further dSSI complications, such as readmissions, the emergence of resistant bacteria, and additional costs. Here, we evaluated the impacts of dSSIs in terms of readmission rates, hospitalization costs, and LoS in a matched case-control study in an academic hospital in The Netherlands. In addition, we investigated predictors for the development of dSSI.

\section{Patients and Methods}

\section{Patients Data}

We performed a matched case-control observational study using the electronic health records at the University Medical
Center Groningen (UMCG), the largest hospital in the Northern Netherlands, comprising of 1339 beds. We included patients whose surgical procedures were conducted between 2014 and 2016, where the data have been validated by the surgeon for dSSI diagnoses and by the Finance Department for the reimbursements. Also, the hospital started the surveillance for SSI began in 2014. Data on clinical characteristics, comorbidities, costing codes, and occurrence of superficial SSIs, dSSIs, and organ/space SSIs diagnoses of anonymized patients were collected. The infection was confirmed by the presence of purulent drainage, abscesses, or other evidence of local infection from deep soft tissues (fascial and muscles) at the incision site. Symptoms experienced by dSSI patients could include localized pain, tenderness, and fever $\left(>38^{\circ} \mathrm{C}\right) .{ }^{9}$ A surgeon or an attending physician at the hospital conducted individual dSSI diagnoses following the ECDC criteria. The ECDC protocol for SSI surveillance defines a dSSI case as an infection acquired within 30 days of non-implant surgery or up to a year after implant surgery. ${ }^{25}$

We matched the surgical specializations and the surgical technique used in patients with dSSI and non-SSI. We categorized the types of surgeries using the ECDC protocol, based on clean (W1), clean-contaminated (W2), contaminated (W3) and dirty wound surgeries (W4). ${ }^{25}$ Clean surgery is defined as a surgical procedure that does not involve the alimentary, respiratory, or genitourinary tracts. Surgical procedures that do not involve penetrating trauma fall under this category. ${ }^{25,26}$ Clean-contaminated surgeries, such as appendectomies, hysterectomies, or surgical procedures relating to oropharyngeal cancer, entail entry into the alimentary, respiratory, or genitourinary tracts without any usual contamination. ${ }^{25,26}$ Contaminated surgeries include coronary bypass or hip replacement, where there is gross spillage during the sterile procedure, ${ }^{27}$ or where there is contact with gallbladder, urine, or the gastrointestinal lumen. Dirty or infected surgeries are characterized by abscesses in visceral organs or infected organs or tissues. ${ }^{26,28,29}$ All of the surgical procedures included in the study are listed in the Supplementary material.

\section{Outcome Measurements}

We considered readmission, LoS in days, and costs of dSSI complications in our analysis. Readmission associated with dSSIs was defined as a subsequent admission within the same hospital that occurred within a 30-day period following the initial hospital discharge. ${ }^{30-32}$ LoS data was sourced directly from the hospital discharge records for each admission. Costs were based on the 
method within the Dutch healthcare systems labelled "the Dutch diagnoses related groups (DRGs) (in Dutch: "Diagnose Behandeling Combinaties" [DBCs]) within specialized hospital care (https://www.vergelijkdezorgver zekeringen.nl/dbc-declaratiecode/). This is different from the common established DRGs that are used widely worldwide. These groups are based upon a combination of treating specialty, diagnosis, and procedures and are uniformly scored throughout the country. We applied hospital reference prices of these groups for the period 2014-2016. ${ }^{33-35}$ The World Health Organization (WHO) considers the use of prophylactic antibiotics as an important measure in SSI prevention. ${ }^{36}$ We therefore additionally evaluated the impacts of prophylactic antibiotics on the outcome of dSSIs. These antibiotics were administered to the patients within a period of 60 minutes prior to an incision being made.

\section{Statistical Analyses}

Data analyses were performed using IBM SPSS statistics version 25 . We presented descriptive data as counts and percentages. Chi-square tests were applied to analyze statistical differences in proportions between case and control groups. We performed univariate and multivariate analyses of the cases to determine the predictors of a dSSI outcome including potentially relevant predictors sex, age, the use of prophylactic antibiotics before the initial incision, types of surgery, surgery sites, and comorbidities. In the multivariate logistic regression model, we minimized the degrees of freedom and excluded variables with a number of events below ten by merging agerelated covariates into two categories ( $<65 \mathrm{vs.} \geq 65$ years) and by the categorizing four types of surgery W1 through W4. In addition, we used Chi-square to test the goodness-of-fit of the logistic model. Each risk was presented as an odds ratio (OR) together with a $95 \%$ confidence interval (CI). The variables that met the criteria of the $95 \%$ CI not including 1 were considered significant and included in the analyses.

We assessed the impact of dSSI on the LoS outcome with a time to event analysis, the event being the discharge of the patient. First, a Kaplan-Meier test and Log Rank test were performed to assess the differences in LoSs, measured as the times to hospital discharge between dSSI patients and those in the control group within the 120days time frame. Differences in mean costs were analyzed using a two-sided $t$-test. Because the data on costs were highly skewed, we performed bootstraps for 1000 samples. ${ }^{37,38}$ Second, we assessed the predictors for the LoS outcome using a Cox-regression analysis with categorical backward selection on variables of having dSSI, sex, age, types of surgery, and comorbidities. Hazard ratios (HRs) lower than 1 indicated extended LoS, while HR higher than 1 indicated shorter LoS. ${ }^{39}$ Statistical differences were considered significant at a $p$-value $<0.05$.

\section{Results}

We examined a total of 12,285 registered patients who were admitted and underwent various surgical procedures between 2014 and 2016 in all surgical departments. Of those, infections were reported for 1624 (13.2\%) patients while no infections were reported 10,661 patients (86.8\%). An SSI rate was documented at $5.3 \%$ of the total surgical procedures, while dSSI was diagnosed in $393(3.2 \%)$ that were included in the analyses as cases. There was no report of patients with organ/space SSIs. The control group comprised 2864 patients (23\%) who fulfilled the matching criteria relating to surgical procedures. The selection of the patients investigated in this study is shown in Figure 1.

Fifty-two percent of the patients were men with an average age of $52.9( \pm 17.9)$ years compared to females with a mean age of $51.7( \pm 16.9)$ years. Out of 393 cases and 2864 controls, 343 $(87 \%)$ and 2307 (81\%) patients, respectively, were readmitted within 30 days of their surgical procedures. Most initial admissions (32\%) and readmissions (33\%) concerned abdominal surgeries. Seventy-nine percent of patients with neoplasms (281 out of 356) were readmitted with neoplasms being the most frequently observed comorbidity $(10.9 \%)$. The baseline characteristics of the patients are summarized in Table 1. Incidences of dSSI were lower among patients who received prophylactic antibiotics prior to undergoing surgery compared with such incidences among those who did not receive prophylactic treatment ( $38 \%$ vs. $62 \%$, respectively, $\mathrm{p}<0.001$ ).

The median LoS for all patients was 5 days $\left(\mathrm{P}_{25}-\mathrm{P}_{75}\right.$ : 2-10). Patients with dSSIs stayed longer in the hospital compared to those without SSI (Log-Rank $p$-value $\leq 0.001$ ). The median LoS was 7 days $\left(\mathrm{P}_{25}-\mathrm{P}_{75}: 2.5-14.5\right)$ for dSSI patients and 5 days $\left(\mathrm{P}_{25}-\mathrm{P}_{75}: 1-9\right)$ for non-SSI patients. Kaplan-Meier plots of LoS differences between dSSI and non-SSI patients are depicted in Figure 2. Having dSSI and being 65 years or older were the two independent factors associated with prolonged LoS, with HRs of $0.742(95 \% \mathrm{CI}$ : 0.679-0.809), and 0.809 (95\% CI: 0.750-0.873), respectively. The multivariate logistic regression model for prolonged LoS outcome are presented in Table 2.

The mean cost of clean surgery was $€ 4,391$ per patient, with respective mean costs of $€ 5,505$ and $€ 4,247$ for dSSI 


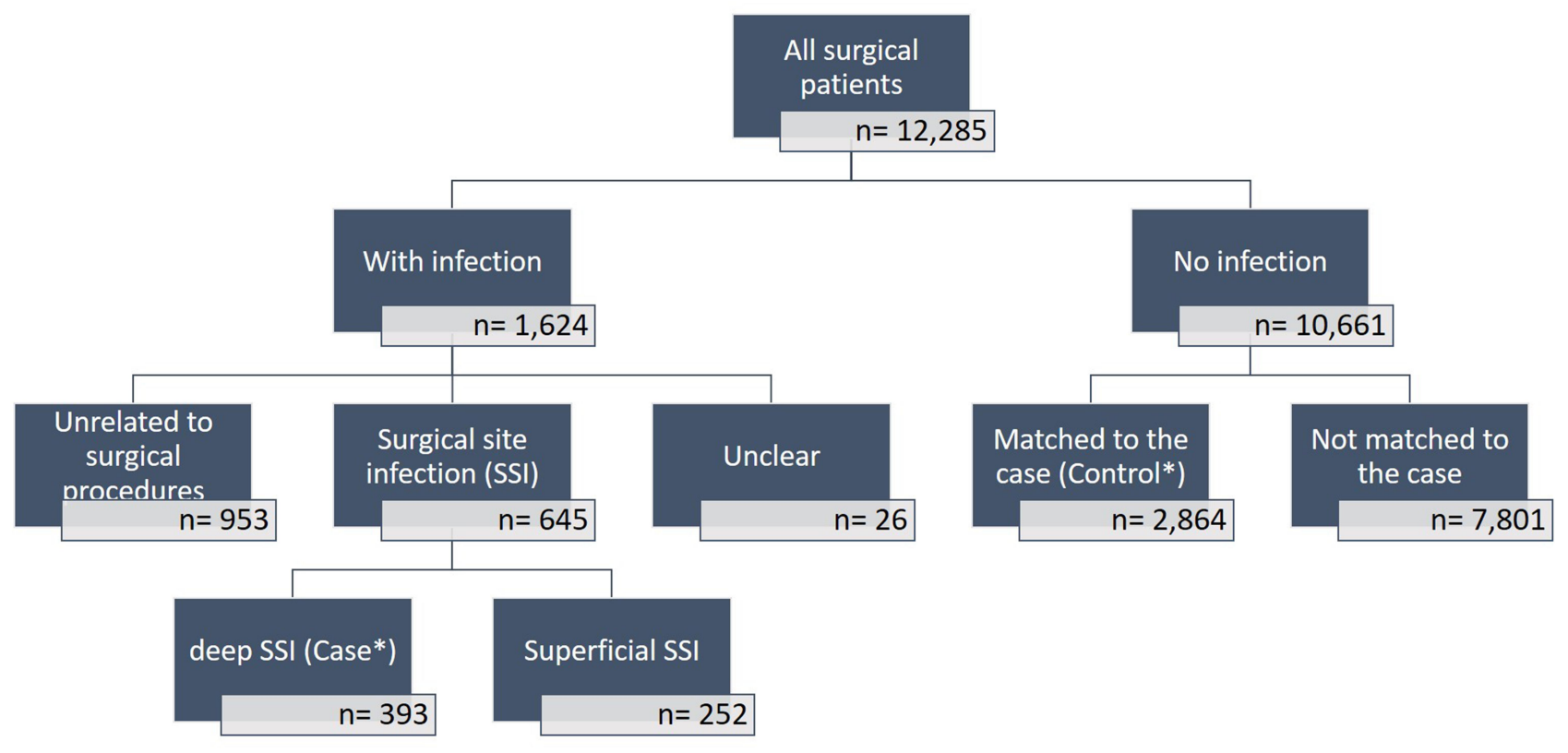

Figure I Flow-chart depicting the process of selecting deep SSI (case) and the control.

and non-SSI patients (a difference of $€ 1,258$; $\mathrm{p}<0.001$ ). The mean cost of clean-contaminated surgeries per patient was estimated at $€ 6,788$, with respective mean costs of $€ 12,479$ and $€ 6,182$ for dSSI and non-SSI patients (a twofold difference; $\mathrm{p}<0.001)$. The average hospitalization cost was highest for contaminated surgeries with at an average of $€ 8,219$ per patient, with $€ 13,170$ for dSSI and $€ 7,424$ for non-SSI (equivalent to 1.8 times higher; $\mathrm{p}<0.001)$. Dirty surgery showed the lowest mean cost $(€ 3,027)$ among all types of surgical procedures. Overall, the average cost for all cases was $€ 5,844( \pm 121)$ per patient, with respective mean costs of $€ 9,016( \pm 343)$ and $€ 5,409( \pm 120)$ for dSSI and non-SSI (cost difference of $€ 3,607 ; \mathrm{p}<0.001)$. Table 3 lists the hospitalization costs per patient for each type of surgery.

In the multivariate analyses, we excluded the diabetes mellitus covariate as the number of patients in the control group was too small $(\mathrm{n}=8)$. There were two independent variables turning out as factors for dSSI: age $\geq 65$ (OR: 1.334; $95 \%$ CI: 1.036-1.720) and neoplasm (OR: 2.050; 95\% CI: $1.473-$ 2.854). The use of prophylactic antibiotics before the initial incision showed a protective effect against dSSI (OR: 0.424; 95\% CI: $0.344-0.537)$. The results of the univariate and multivariate analyses are summarized in Table 4.

\section{Discussion}

Our findings indicated that the costs, LoS and readmission rates of dSSI cases were higher than those of non-SSI cases in all types of surgeries. Clean surgeries associated with the head and neck, thorax, extremities, and spine were performed most frequently in this hospital, followed by contaminated and dirty surgeries in which the abdominal region was commonly the targeted site. Our findings documented that having $\mathrm{dSSI}$ and being aged $\geq 65$ were the two independent factors for extended LoS. Notably, elderly patients ( $\geq 65$ years) and patients with neoplasms or cardiovascular diseases would have a higher risk of dSSI, while patients receiving prophylactic antibiotics would have a lower risk of dSSI. This finding supports enhancing developed facilities for managing infection prevention procedures in the Netherlands.

The hospital under investigation has developed an integrated stewardship with a theragnostic approach, which has been conceptualized in a multi-faceted model of antimicrobial (A), infection prevention (I), and diagnostic (D) stewardship, labeled AID model. AID involves trained staff, covering diverse specialties, and is dedicated to controlling hospital-acquired infections and stemming further antimicrobial resistance. ${ }^{16,17,40}$ The dSSI rates in our study were documented in the range of PREZIES findings that were between $0.2 \%$ and $5.9 \%$ of all surgical procedures. ${ }^{20}$ In a systematic review, the global incidence of SSIs ranged from $0 \%$ to $70 \%{ }^{7}$ The rates of SSI depend on the surgery types and locations as well as prophylactic treatment. ${ }^{7,41} \mathrm{WHO}$ and ECDC also revealed that the use of prophylactic antibiotics prior to initial incision reflects a proper and 
Table I Baseline Characteristics of Patients with dSSI and Non-SSI During Initial Admissions and Readmissions

\begin{tabular}{|c|c|c|c|c|c|c|c|c|}
\hline \multirow[t]{2}{*}{ Characteristics } & \multicolumn{4}{|c|}{ Initial Surgical Admission, $n(\%)$} & \multicolumn{4}{|c|}{ Readmitted, $n(\%)$} \\
\hline & $\begin{array}{l}\text { All Patients } \\
(n=3257)\end{array}$ & $\begin{array}{l}\text { dSSI } \\
(n=393)\end{array}$ & $\begin{array}{l}\text { Non-SSI } \\
(n=2864)\end{array}$ & $\begin{array}{l}p- \\
\text { value }\end{array}$ & $\begin{array}{l}\text { All Patients } \\
(n=2650)\end{array}$ & $\begin{array}{l}\text { dSSI } \\
(n=343)\end{array}$ & $\begin{array}{l}\text { Non-SSI } \\
(n=2307)\end{array}$ & $\begin{array}{l}p- \\
\text { value }\end{array}$ \\
\hline \multicolumn{9}{|l|}{ Sex } \\
\hline Male & $1512(46.4)$ & $202(51.4)$ & $1310(45.7)$ & $0.035^{*}$ & $1256(47.4)$ & $183(53.4)$ & $1073(46.5)$ & $0.018^{*}$ \\
\hline Female & $1745(53.6)$ & $191(48.6)$ & $1554(54.3)$ & & $1394(52.6)$ & $160(46.6)$ & $1234(53.5)$ & \\
\hline \multicolumn{9}{|l|}{ Age } \\
\hline$<65$ years & $2466(75.7)$ & $269(68.4)$ & $2197(76.7)$ & $<0.001 *$ & $2030(76.6)$ & $234(68.2)$ & $1796(77.9)$ & $<0.001^{*}$ \\
\hline$\geq 65$ years & $790(24.3)$ & $124(31.6)$ & $666(23.3)$ & & $620(23.4)$ & $109(31.8)$ & $511(22.1)$ & \\
\hline \multicolumn{9}{|l|}{$\begin{array}{l}\text { Antibiotic } \\
\text { prophylaxis }\end{array}$} \\
\hline No & $1562(48.0)$ & $242(61.6)$ & $1320(46.1)$ & $<0.001 *$ & $1252(47.2)$ & $207(60.3)$ & $1045(45.3)$ & $<0.001 *$ \\
\hline Yes & $1695(52.0)$ & $|5|(38.4)$ & I544(53.9) & & 1398(52.8) & $136(39.7)$ & $1262(54.7)$ & \\
\hline \multicolumn{9}{|l|}{ Types of surgery } \\
\hline Clean & $|57|(48.2)$ & $180(45.8)$ & $|39|(48.6)$ & 0.329 & $130 \mid(49.1)$ & $16 \mid(46.9)$ & $1140(49.4)$ & 0.392 \\
\hline Clean- & $572(17.6)$ & $55(14.0)$ & $517(18.1)$ & 0.056 & $400(15.1)$ & $46(13.4)$ & $354(15.3)$ & 0.351 \\
\hline Contaminated & $940(28.9)$ & $130(33.1)$ & $810(28.3)$ & 0.056 & $788(20.7)$ & $109(31.8)$ & $679(29.4)$ & 0.375 \\
\hline Dirty & $174(5.3)$ & $28(7.1)$ & $146(5.1)$ & 0.094 & $161(6.1)$ & $27(7.9)$ & $134(5.8)$ & 0.136 \\
\hline \multicolumn{9}{|l|}{ Location of surgery } \\
\hline Head and neck & $329(10.1)$ & $83(21.1)$ & $246(8.6)$ & $<0.001 *$ & $308(11.6)$ & $79(23.0)$ & $229(9.9)$ & $<0.00 I^{*}$ \\
\hline Upper-extremity & $82(2.5)$ & $25(6.4)$ & $57(2.0)$ & $<0.001 *$ & $57(2.2)$ & $23(6.7)$ & $34(1.5)$ & $<0.001 *$ \\
\hline Thorax & $558(17.1)$ & $42(10.7)$ & $516(18.0)$ & $<0.001 *$ & $380(14.3)$ & $28(8.2)$ & $352(15.3)$ & $<0.00 I^{*}$ \\
\hline Abdomen & $1055(32.4)$ & 153(38.9) & $902(31.5)$ & $0.003^{*}$ & $865(32.6)$ & $130(37.9)$ & $735(85.0)$ & $0.026^{*}$ \\
\hline Spine & $791(24.3)$ & $28(7.1)$ & $763(26.6)$ & $<0.001 *$ & $672(25.4)$ & $26(7.6)$ & $646(28.0)$ & $<0.001 *$ \\
\hline Lower-extremity & $442(13.6)$ & $62(15.8)$ & $380(13.3)$ & 0.173 & $368(13.9)$ & $57(16.6)$ & $311(13.5)$ & 0.117 \\
\hline $\begin{array}{l}\text { Organ } \\
\text { transplantation }\end{array}$ & $102(3.1)$ & $7(6.9)$ & $95(3.30)$ & 0.101 & $95(3.6)$ & $6(1.7)$ & $89(3.9)$ & 0.050 \\
\hline \multicolumn{9}{|l|}{ Comorbidities } \\
\hline Neoplasm & $356(10.9)$ & $62(15.8)$ & $294(10.3)$ & $<0.001 *$ & $28 I(10.6)$ & $55(16.0)$ & $226(9.8)$ & $0.001 *$ \\
\hline Diabetes mellitus & $20(0.6)$ & $12(3.1)$ & $8(0.3)$ & $<0.001 *$ & $20(0.8)$ & $12(3.5)$ & $8(0.3)$ & $<0.00 I^{*}$ \\
\hline $\begin{array}{l}\text { Cardiovascular } \\
\text { diseases }\end{array}$ & $196(6.0)$ & $12(3.1)$ & $184(6.4)$ & $0.011 *$ & $112(4.2)$ & $10(2.9)$ & $102(4.4)$ & 0.250 \\
\hline
\end{tabular}

Note: *Statistically significant, $p<0.05$.

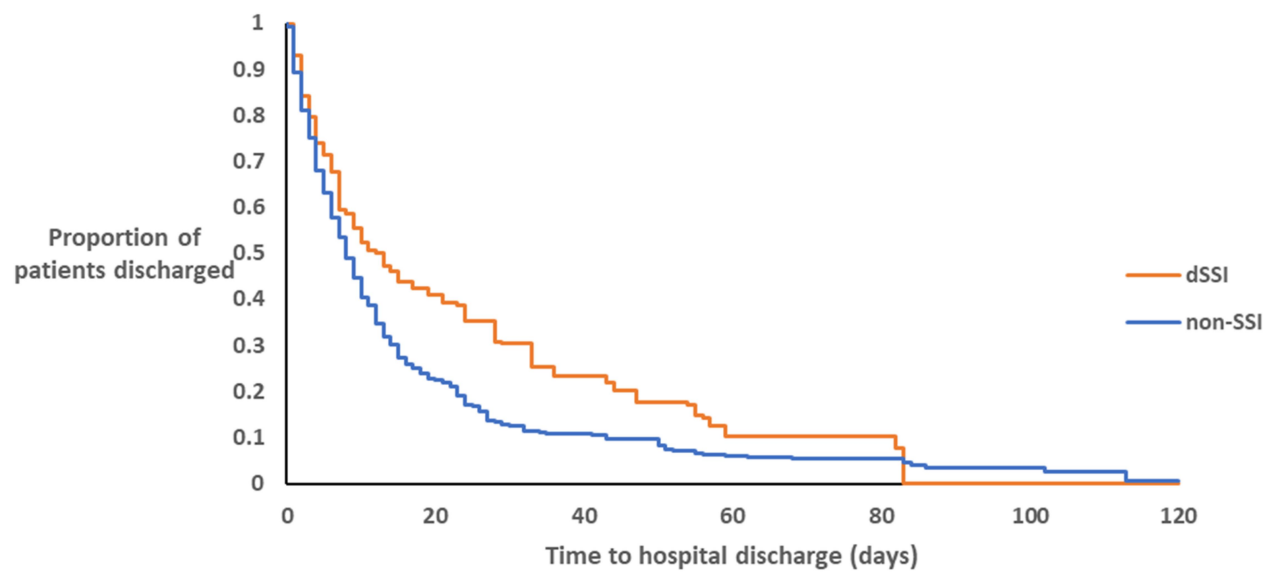

Figure 2 Kaplan-Meier curve of the lengths-of-stay of dSSI patients and controls with non-SSIs (LogRank, $\mathrm{p}<0.00 \mathrm{I}$ )

Note: There was no any hospital discharge after day-82 among dSSI patients 
Table 2 The Multivariate Logistic Regression Model for Length of Stay

\begin{tabular}{|c|c|c|c|c|c|c|c|}
\hline Variables & B & SE & Wald & $p$-value & HR & Lower 95\% CI HR & Upper $95 \%$ Cl HR \\
\hline \multicolumn{8}{|l|}{ Having dSSI } \\
\hline No & Ref & & & & Ref & & \\
\hline Yes & -0.299 & 0.045 & 44.683 & $<0.001$ & $0.742 *$ & 0.679 & 0.809 \\
\hline \multicolumn{8}{|l|}{ Sex } \\
\hline Male & Ref & & & & Ref & & \\
\hline Female & 0.049 & 0.030 & 2.624 & 0.105 & 1.050 & 0.990 & 1.115 \\
\hline \multicolumn{8}{|l|}{ Age } \\
\hline$<65$ years & Ref & & & & Ref & & \\
\hline$\geq 65$ years & -0.212 & 0.039 & 29.747 & $<0.001$ & $0.809 *$ & 0.750 & 0.873 \\
\hline \multicolumn{8}{|l|}{ Antibiotic prophylaxis } \\
\hline No & Ref & & & & Ref & & \\
\hline Yes & 0.092 & 0.031 & 8.615 & 0.003 & $1.096 *$ & 1.031 & 1.166 \\
\hline \multicolumn{8}{|l|}{ Types of surgery } \\
\hline Clean & Ref & & & & Ref & & \\
\hline Clean-contaminated & 0.015 & 0.046 & 0.112 & 0.738 & 1.016 & 0.928 & 1.112 \\
\hline Contaminated & 0.105 & 0.037 & 8.053 & 0.005 & $1.110 *$ & 1.033 & 1.193 \\
\hline Dirty & 0.291 & 0.069 & 17.600 & $<0.001$ & $1.338 *$ & 1.168 & 1.533 \\
\hline \multicolumn{8}{|l|}{ Comorbidities } \\
\hline Neoplasm & 0.187 & 0.045 & 17.328 & $<0.001$ & $1.206 *$ & 1.104 & 1.317 \\
\hline Cardiovascular diseases & -0.046 & 0.084 & 0.299 & 0.585 & 0.955 & $0.88 I$ & 1.125 \\
\hline
\end{tabular}

Notes: *Statistically significant; the $95 \% \mathrm{Cl}$ does not include a value of I.

Abbreviations: $\mathrm{dSSI}$, deep surgical site infection; $\mathrm{Cl}$, confidence interval; $\mathrm{HR}$, hazard ratio; Ref, reference.

successful modality to decrease SSI incidence. ${ }^{25,42}$ This illustrates the crucial moment of the preoperative phase to prevent SSIs by adherence to adequate uses of prophylactic antibiotics relating to their selection, optimal dosing, and timing. ${ }^{7,43}$ Related monitoring relating of post-operative measures focuses on the prolonged use of prophylactic antibiotics and the timing of drain removal. ${ }^{42}$

Our findings show that the hospitalization cost for dSSI was higher compared with non-SSI. The burden of additional costs incurred for dSSI cases is plausibly reflected in prolonged hospitalization, as well as readmissions. ${ }^{21,44-46}$ As a comparative reference, respective SSI and non-SSI costs of $€ 1,011$ and $€ 1,167$ per patient day may serve as reported by a German hospital geographically close to the hospital in Groningen. The reported LoS for those patients ranged between 34.4 and 16.5 days with total hospitalization costs per SSI and non-SSI patients of $€ 36,261$ and $€ 13,356$, respectively. ${ }^{47,48}$ In addition to the impact of SSIs on prolonged LoS, a previous study in cardiac surgery showed that SSIs evidently had a significant impact on LoS and costs as indicated by 3.8 -fold and 5.8 fold increases, respectively, as compared with these measures for non-SSI patients. ${ }^{49}$
Approximately $87 \%$ of dSSI patients in the present study were readmitted compared with $81 \%$ of non-SSI patients. Readmissions were often due to the presence of comorbidities such as neoplasm, diabetes, and cardiovascular diseases. Evidently, readmission contributes to high costs. Wick et al, estimated that the cost of surgical readmission after colorectal surgery in the United States was US $\$ 8,885$ per stay with a mean $\operatorname{LoS}$ of 8 days. ${ }^{50}$ A previous study found that more than $50 \%$ of SSI cases were readmitted for revision surgery because of wound infections at the surgery sites and other post-surgical complications such as bleeding, dehydration, renal failure, embolism, cardiovascular events, and ileus. ${ }^{1,3}$ Other studies indicate that approximately $76-97 \%$ of SSI patients are readmitted at least once for revision surgery or wound debridement. ${ }^{51,52}$ Post-surgical readmission could be substituted by performing a home visit or providing outpatient care within an earlier 30-day medical follow-up after surgical discharge, possibly alleviating the costs. Jencks et al, reported that the post-surgery monitoring for infections effectively reduced readmission rates. ${ }^{53}$ Additionally, the timing of unanticipated readmissions after surgical 
Table 3 Hospitalization Cost per Patient Categorized by the Types of Surgery

\begin{tabular}{|l|l|l|l|l|l|}
\hline Costs, Mean (SE) & All Cases & dSSI Cases & Non-SSI Cases & Cost Difference & $p$-value \\
\hline Clean surgery & $€ 4,39 I . I I(I 09.2 I)$ & $€ 5,505.08(32 I .26)$ & $€ 4,246.95(I I 3.06)$ & $€ I, 258.13(34 I .4 I)$ & $<0.00 I^{*}$ \\
Clean-contaminated surgery & $€ 6,787.76(447.29)$ & $€ I 2,478.6 I(I, 420.59)$ & $€ 6, I 82.34(466.9 I)$ & $€ 6,296.27(I, 494.24)$ & $<0.00 I^{*}$ \\
Contaminated surgery & $€ 8,2 I 8.74(23 I .74)$ & $€ I 3, I 70 . I I(I, 0 I 9.0 I)$ & $€ 7,424.07(200.30)$ & $€ 5,746.03(644.93)$ & $<0.00 I *$ \\
Dirty surgery & $€ 3,027.80(298.48)$ & $€ 5,497.86(I, 027.58)$ & $€ 2,554.09(28 I .70)$ & $€ 2,943.76(783.10)$ & $<0.00 I *$ \\
\hline
\end{tabular}

Note: *Statistically significant, $p<0.05$.

Abbreviation: SE, standard error.

Table 4 The Multivariate Logistic Regression Model for Deep Surgical-Site Infections

\begin{tabular}{|c|c|c|c|c|}
\hline \multirow[t]{2}{*}{ Characteristics } & \multicolumn{2}{|c|}{ Univariate Analysis } & \multicolumn{2}{|c|}{ Multivariate Analysis } \\
\hline & Crude OR & $95 \% \mathrm{Cl}$ & Adjusted OR & $95 \% \mathrm{Cl}$ \\
\hline \multicolumn{5}{|l|}{ Sex } \\
\hline Male & Ref & & Ref & \\
\hline Female & 0.797 & $0.645-0.984 *$ & 0.835 & $0.670-1.034$ \\
\hline \multicolumn{5}{|l|}{ Age } \\
\hline$<65$ years & Ref & & Ref & \\
\hline$\geq 65$ years & 1.521 & $1.209-1.913 *$ & 1.977 & $1.542-2.534^{*}$ \\
\hline \multicolumn{5}{|l|}{ Antibiotic prophylaxis } \\
\hline No & Ref & & Ref & \\
\hline Yes & 0.533 & $0.430-0.662 *$ & 0.459 & $0.366-0.575^{*}$ \\
\hline \multicolumn{5}{|l|}{ Types of surgery } \\
\hline Clean & Ref & & Ref & \\
\hline Clean-contaminated & 0.822 & $0.598-1.130$ & 0.793 & $0.564-1.114$ \\
\hline Contaminated & 1.240 & $0.974-1.579$ & 1.101 & $0.847-|.43|$ \\
\hline Dirty & 1.482 & $0.96 \mathrm{I}-2.285$ & 1.367 & $0.879-2.127$ \\
\hline \multicolumn{5}{|l|}{ Comorbidities } \\
\hline Neoplasm & 1.637 & $1.217-2.203 *$ & 1.466 & $1.063-2.02 I^{*}$ \\
\hline Cardiovascular diseases & 0.459 & $0.253-0.83 I^{*}$ & 0.372 & $0.197-0.702^{*}$ \\
\hline
\end{tabular}

Notes: *Statistically significant; the $95 \% \mathrm{Cl}$ does not include a value of $\mathrm{I}$.

Abbreviations: $\mathrm{Cl}$, confident interval; OR, odds ratio; Ref, reference.

discharge, which is mainly contingent on the emergence of crises relating to serious complications or existing comorbidities, requires further investigation. ${ }^{1}$ Moreover, in our study, dSSI patients aged 65 years or above were significantly at higher risk for readmissions. This finding is in line with that of Kaye et al, who reported that the LoS for hospitalization and post-surgery readmission of elderly patients with SSIs was three times greater than that for non-SSI patients. Moreover, the mean cost incurred by older patients was US\$ 43,970, which was double the cost incurred by non-SSI patients. ${ }^{54}$

In clean surgeries, such as thyroidectomies, the prophylactic use of antimicrobial agents is unlikely to be necessary. ${ }^{55}$ Reported SSI rates for clean surgeries ranged between $0 \%$ and $3 \% .^{14,56}$ The incidence of SSI in clean- contaminated surgeries is reported to range between $3 \%$ and $11 \%,{ }^{13,14}$ while the SSI rate for contaminated surgeries is approximately $15 \%$ of all surgical procedures. ${ }^{14}$ Additionally, a high SSI rate of at least $20 \%$ has been reported for laparoscopies performed in cases of perforated appendicitis, which are considered dirty surgeries. ${ }^{15}$ In line with our findings, a previous systematic review and an original study reported that the risk of SSI is high for orthopedic and general surgery involving the thorax, abdomen, spine, and lower extremities. ${ }^{1,7}$ The reason for these findings may be that the risk of SSI is also contingent on the performance of individual procedures that facilitate the invasion of underlying pathogens. Furthermore, our findings showed that the total hospitalization costs for dirty procedures were estimated higher compared to those for 
contaminated surgery. This could be explained that contaminated surgeries mostly involved gastrointestinal tract and deep organ which was the surgeon performing major procedures. On the other hand, dirty surgeries predominantly concerned cases of drainage of the abscess.

To the best of our knowledge, this is the first study to combine a comprehensive analysis of the impacts of dSSI on the hospitalization costs, and LoS. However, it has some limitations. First, we used data sourced from one academic hospital only and this hospital's DBC coding for inpatient reimbursement, which may have led to the exclusion of some patients who received medication from the community or from general practitioners. Also, as our limitation of not analyzing the emergency or unplanned surgeries, there would be differences in outcomes, especially for the cost. Nevertheless, in the Netherlands, elective surgeries are predominant. Second, we applied a payer-based analytical perspective and did not consider indirect costs, specifically those associated with productivity losses. Third, this study did not cover the preferences of patients with dSSI and post-surgery, for example, regarding the quality of life outcomes. ${ }^{57}$ Fourth, in this study, we also found a few patients with bacteremia. However, numbers were too small to perform any analyses on the correlation between dSSI and bacteremia. Fifth, the generalization of the findings to other countries, for example, in the context of low-middle income countries may require adjustments relating to clinical-economic impacts and local healthcare systems. Moreover, other parameters in SSI prevention bundles, such as shaving procedure, disinfections, operating room category, door opening frequency, were not taken into account in the analyses since the lack of relevant data. Overall, however, the findings of this study endorsed the implementation of infection prevention measures with quintessential AID stewardship within a hospital setting.

\section{Conclusion}

The impacts of dSSI manifest itself not only during the course of the disease but also in its consequences, as reflected in readmission rates, extended LoS, and additional costs. Identified independent variables for dSSI risk, notably patients' older age and neoplasm comorbidity, should intensively be monitored, and prophylactic antibiotics should definitely be considered in such cases. In addition, patients having dSSI and being 65 years and over both had an association with prolonged LoS. Further research should be directed towards evaluating patients' characteristics in relation to dSSI impacts on an individual level rather than our group-based approach to allow a personalized strategy in infection prevention.

\section{Abbreviations}

AID, antimicrobial, infection prevention, and diagnostic; AMS, antimicrobial stewardship; CI, confidence interval; DBC, Diagnose Behandeling Combinatie; DGS, diagnostic stewardship; dSSI, deep surgical site infection; EUCAST, European Committee on Antimicrobial Susceptibility Testing; GNB, Gram-negative bacteria; HR, hazard ratio; ICU, intensive care unit; LoS, length of stay; MRSA, methicillin-resistant Staphylococcus aureus; OR, odds ratio; SE, standard error; SSI, surgical site infection; UMCG, University Medical Center Groningen.

\section{Ethical Approval}

The Medical Ethical Review Committee of the UMCG waived the requirement for individual informed consent because this study concerns a retrospective database study (registration number M19110329). For the purpose of confidentiality, the data were collected and held anonymously. Also, the study followed the agreement stated in the Declaration of Helsinki (Ethical Principles for Medical Research Involving Human Subject version 2013). ${ }^{58}$

\section{Acknowledgments}

We would like to thank Igor van der Weide for providing the clinical data and reimbursement codes for this study. We also thank Josue Almansa Ortiz for verifying the statistical results. This study was supported by the Groningen University Institute for Drug Exploration (GUIDE) of the Graduate School of Medical Sciences at the University Medical Center Groningen (UMCG) in the Netherlands. The study also received support from the Directorate General of Higher Education (DIKTI), the Ministry of Education and Culture of the Republic of Indonesia [No. 224/D3.2/PG/2016] and the Faculty of Medicine at Universitas Airlangga [No. 305/ UN3.5/SDM/2016]. In addition, CL was supported by the European Commission Horizon 2020 Framework Marie Skłodowska-Curie Actions (grant agreement number: 713660-PRONKJEWAIL-H2020-MSCA-COFUND-2015).

\section{Author Contributions}

All authors contributed to data analysis, drafting or revising the article, have agreed on the journal to which the article will be submitted, gave final approval of the version to be published, and agree to be accountable for all aspects of the work. 


\section{Disclosure}

Outside of this work, Prof. Postma reports receiving various grants and honoraria from both public (EU, WHO) and various private (GSK, Pfizer, Astra, Sobi, MSD, Sanofi, Sequiris, Roche, Novartis, IQVIA, RJW \& Partners, Biomarin, Roche Diagnostics, Mundi Pharma, Boehringer Ingelheim, Parexel, Novovax, Heron, Atheneum, Creativ Ceuticals, Daiichi Sankyo and Merck) parties. Prof. Postma is also shareholder of Pharmacoeconomics Advice Groningen and Ingress Health, and advisor to Asc Academics Groningen and Health-Ecore. The authors report no other potential conflicts of interest for this work.

\section{References}

1. Merkow RP, Ju MH, Chung JW, et al. Underlying reasons associated with hospital readmission following surgery in the United States. JAMA. 2015;313(5):483-495. doi:10.1001/jama.2014.18614

2. Ou L, Chen J, Hillman K, et al. The impact of post-operative sepsis on mortality after hospital discharge among elective surgical patients: a population-based cohort study. Crit Care. 2017;21(1):34. doi:10.1186/ s13054-016-1596-7

3. Cristofolini M, Worlitzsch D, Wienke A, Silber R-E, Borneff-Lipp M. Surgical site infections after coronary artery bypass graft surgery: incidence, perioperative hospital stay, readmissions, and revision surgeries. Infection. 2012;40(4):397-404. doi:10.1007/s15010-012-0275-0

4. Fried E, Weissman C, Sprung C. Postoperative sepsis. Curr Opin Crit Care. 2011;17(4):396-401. doi:10.1097/MCC.0b013e328348bee2

5. Vogel TR, Dombrovskiy VY, Carson JL, Graham AM, Lowry SF. Postoperative sepsis in the United States. Ann Surg. 2010;252 (6):1065-1071. doi:10.1097/SLA.0b013e3181dcf36e

6. Mu Y, Edwards JR, Horan TC, Berrios-Torres SI, Fridkin SK. Improving risk-adjusted measures of surgical site infection for the National Healthcare Safely Network. Infect Control Hosp Epidemiol. 2011;32(10):970-986. doi:10.1086/662016

7. Purba AKR, Setiawan D, Bathoorn E, Postma MJ, Dik J-WH, Friedrich AW. Prevention of surgical site infections: a systematic review of cost analyses in the use of prophylactic antibiotics. Front Pharmacol. 2018;9:776. doi:10.3389/fphar.2018.00776

8. Cassini A, Plachouras D, Eckmanns T, et al. Burden of six healthcare-associated infections on European Population Health: estimating incidence-based disability-adjusted life years through a Population Prevalence-Based Modelling Study. PLoS Med. 2016;13(10): e1002150. doi:10.1371/journal.pmed.1002150

9. Horan TC, Gaynes RP, Martone WJ, Jarvis WR, Emori TG. CDC definitions of nosocomial surgical site infections, 1992: a modification of CDC definitions of surgical wound infections. Infect Control Hosp Epidemiol. 1992;13(10):606-608. doi:10.2307/30148464

10. Kaye KS, Schmit K, Pieper C, et al. The effect of increasing age on the risk of surgical site infection. $J$ Infect Dis. 2005;191(7):10561062. doi: $10.1086 / 428626$

11. Neumayer L, Hosokawa P, Itani K, El-Tamer M, Henderson WG, Khuri SF. Multivariable predictors of postoperative surgical site infection after general and vascular surgery: results from the patient safety in surgery study. J Am Coll Surg. 2007;204(6):1178-1187. doi:10.1016/j.jamcollsurg.2007.03.022

12. Culver DH, Horan TC, Gaynes RP, et al. Surgical wound infection rates by wound class, operative procedure, and patient risk index. National Nosocomial Infections Surveillance System. Am J Med. 1991;91(3):152S-157S. doi:10.1016/0002-9343(91)90361-z
13. Busch C-J, Knecht R, Munscher A, Matern J, Dalchow C, Lorincz BB. Postoperative antibiotic prophylaxis in clean-contaminated head and neck oncologic surgery: a retrospective cohort study. Eur Arch Otorhinolaryngol. 2016;273(9):2805-2811. doi:10.1007/s00405-0153856-6

14. Shrestha S, Wenju P, Shrestha R, Karmacharya RM. Incidence and risk factors of surgical site infections in Kathmandu University Hospital, Kavre, Nepal. Kathmandu Univ Med J (KUMJ). 2016;14(54):107-111.

15. Galli R, Banz V, Fenner H, Metzger J. Laparoscopic approach in perforated appendicitis: increased incidence of surgical site infection? Surg Endosc. 2013;27(8):2928-2933. doi:10.1007/s00464-013-2858-y

16. Dik J-WH, Poelman R, Friedrich AW, et al. An integrated stewardship model: antimicrobial, infection prevention and diagnostic (AID). Future Microbiol. 2016;11(1):93-102. doi:10.2217/fmb.15.99

17. Friedrich AW. Control of hospital acquired infections and antimicrobial resistance in Europe: the way to go. Wien Med Wochenschr. 2019;169(Suppl 1):25-30. doi:10.1007/s10354-018-0676-5

18. Koek MBG, van der Kooi TII, Stigter FCA, et al. Burden of surgical site infections in the Netherlands: cost analyses and disabilityadjusted life years. $J$ Hosp Infect. 2019;103(3):293-302. doi:10.1016/j.jhin.2019.07.010

19. Kivi M, Manniën J, Wille JC, van den Hof S. Surgical site infection surveillance and the predictive power of the National Nosocomial Infection Surveillance index as compared with alternative determinants in The Netherlands. Am J Infect Control. 2008;36(3, Supplement):S27-S31. doi:10.1016/j.ajic.2007.07.006

20. Mannien J, van den Hof S, Brandt C, Behnke M, Wille JC, Gastmeier P. Comparison of the National Surgical Site Infection surveillance data between The Netherlands and Germany: PREZIES versus KISS. J Hosp Infect. 2007;66(3):224-231. doi:10.1016/j.jhin.2007.03.024

21. Coello R, Charlett A, Wilson J, Ward V, Pearson A, Borriello P. Adverse impact of surgical site infections in English hospitals. $J$ Hosp Infect. 2005;60(2):93-103. doi:10.1016/j.jhin.2004.10.019

22. Lawson EH, Hall BL, Ko CY. Risk factors for superficial vs deep/ organ-space surgical site infections: implications for quality improvement initiatives. JAMA Surg. 2013;148(9):849-858. doi:10.1001/ jamasurg.2013.2925

23. European Centre for Disease Prevention and Control. Surgical site infections. Available from: https://www.ecdc.europa.eu/en/publica tions-data/directory-guidance-prevention-and-control/healthcare-asso ciated-infections-0. Accessed December 2, 2019.

24. Health NCC for W and C. Surgical Site Infection: Prevention and Treatment of Surgical Site Infection. London, The United Kingdom; 2008.

25. European Centre for Disease Prevention and Control (ECDC). Surveillance of surgical site infections and prevention indicators in European hospitals. 2017. Available from: https://www.ecdc.europa. $\mathrm{eu} /$ sites/portal/files/documents/HAI-Net-SSI-protocol-v2.2.pdf. Accessed January 17, 2020.

26. Garner JS. CDC guideline for prevention of surgical wound infections, 1985. Supersedes guideline for prevention of surgical wound infections published in 1982. (Originally published in November 1985). Revised. Infect Control. 1986;7(3):193-200. doi:10.1017/ S0195941700064080

27. Tacconelli E, Muller NF, Lemmen S, Mutters NT, Hagel S, Meyer E. Infection risk in sterile operative procedures. Dtsch Arztebl Int. 2016;113(16):271-278. doi:10.3238/arztebl.2016.0271

28. Simmons BP. CDC guidelines for the prevention and control of nosocomial infections guideline for prevention of surgical wound infections. Am J Infect Control. 1983;11(4):133-143. doi:10.1016/ 0196-6553(83)90030-5

29. Mangram AJ, Horan TC, Pearson ML, Silver LC, Jarvis WR. Guideline for prevention of surgical site infection, 1999. Centers for Disease Control and Prevention (CDC) hospital infection control practices advisory committee. Am J Infect Control. 1999;27(2):97-132; quiz 133-134; discussion 96. doi:10.1016/S0196-6553(99)70088-X 
30. Hansen LO, Young RS, Hinami K, Leung A, Williams MV. Interventions to reduce 30-day rehospitalization: a systematic review. Ann Intern Med. 2011;155(8):520-528. doi:10.7326/0003-4819-1558-201110180-00008

31. McPhee JT, Nguyen LL, Ho KJ, Ozaki CK, Conte MS, Belkin M. Risk prediction of 30-day readmission after infrainguinal bypass for critical limb ischemia. J Vasc Surg. 2013;57(6):1481-1488. doi:10.1016/j.jvs.2012.11.074

32. Saunders RS, Fernandes-Taylor S, Rathouz PJ, et al. Outpatient follow-up versus 30-day readmission among general and vascular surgery patients: a case for redesigning transitional care. Surgery. 2014;156(4):949-956. doi:10.1016/j.surg.2014.06.041

33. UMCG passantenprijzen 2014. Available from: https://docplayer.nl/ 12632899-Umcg-passantenprijzen-2014-dbc-zorgproducten-verze kerde-zorg-01-06-2014.html. Accessed November 11, 2019.

34. UMCG passantenprijzen 2015. Available from: https://docplayer.nl/ 15645564-Umcg-passantenprijzen-2015-dbc-zorgproducten-verze kerde-zorg-01-01-2015.html. Accessed November 11, 2019.

35. UMCG passantenprijzen 2016. Available from: https://docplayer.nl/ 28813274-Umcg-passantenprijzen-2016-dbc-zorgproducten-verze kerde-zorg-per.html. Accessed November 11, 2019.

36. World Health Organization. Global guidelines on the prevention of surgical site infection. 2016. Available from: https://www.who.int/ gpsc/ssi-prevention-guidelines/en/. Accessed January 1, 2020.

37. Desgagné A, Castilloux AM, Angers JF, LeLorier J. The use of the bootstrap statistical method for the pharmacoeconomic cost analysis of skewed data. Pharmacoeconomics. 1998;13(5 Pt 1):487-497. doi:10.2165/00019053-199813050-00002

38. Rascati KL, Smith MJ, Neilands T. Dealing with skewed data: an example using asthma-related costs of medicaid clients. Clin Ther. 2001;23(3):481-498. doi:10.1016/s0149-2918(01)80052-7

39. Spruance SL, Reid JE, Grace M, Samore M. Hazard ratio in clinical trials. Antimicrob Agents Chemother. 2004;48(8):2787-2792. doi:10.1128/AAC.48.8.2787-2792.2004

40. Dik J-WH, Sinha B, Lokate M, et al. Positive impact of infection prevention on the management of nosocomial outbreaks at an academic hospital. Future Microbiol. 2016;11(10):1249-1259. doi:10.2217/fmb-2016-0030

41. Cosgrove MS. Infection control in the operating room. Crit Care Nurs Clin North Am. 2015;27(1):79-87. doi:10.1016/j.cnc.2014.10.004

42. World Health Organization. Global Guidelines for the Prevention of Surgical Site Infection. Geneva; 2018.

43. Bratzler DW, Dellinger EP, Olsen KM, et al. Clinical practice guidelines for antimicrobial prophylaxis in surgery. Am J Heal Pharm. 2013;70(3):195-283. doi:10.2146/ajhp120568

44. Badia JM, Casey AL, Petrosillo N, Hudson PM, Mitchell SA, Crosby C. Impact of surgical site infection on healthcare costs and patient outcomes: a systematic review in six European countries. J Hosp Infect. 2017;96(1):1-15. doi:10.1016/j.jhin.2017.03.004

45. Kashimura N, Kusachi S, Konishi T, et al. Impact of surgical site infection after colorectal surgery on hospital stay and medical expenditure in Japan. Surg Today. 2012;42(7):639-645. doi:10.1007/ s00595-012-0126-8

Infection and Drug Resistance

\section{Publish your work in this journal}

Infection and Drug Resistance is an international, peer-reviewed openaccess journal that focuses on the optimal treatment of infection (bacterial, fungal and viral) and the development and institution of preventive strategies to minimize the development and spread of resistance. The journal is specifically concerned with the epidemiology of
46. Mahmoud NN, Turpin RS, Yang G, Saunders WB. Impact of surgical site infections on length of stay and costs in selected colorectal procedures. Surg Infect (Larchmt). 2009;10(6):539-544. doi:10.1089/sur.2009.006

47. Graf K, Ott E, Vonberg R-P, et al. Surgical site infections-economic consequences for the health care system. Langenbeck's Arch Surg. 2011;396(4):453-459. doi:10.1007/s00423-011-0772-0

48. Graf K, Ott E, Vonberg R-P, Kuehn C, Haverich A, Chaberny IF. Economic aspects of deep sternal wound infections. Eur J Cardiothorac Surg. 2010;37(4):893-896. doi:10.1016/j.ejcts.2009.10.005

49. Kusachi S, Kashimura N, Konishi T, et al. Length of stay and cost for surgical site infection after abdominal and cardiac surgery in Japanese hospitals: multi-center surveillance. Surg Infect (Larchmt). 2012;13(4):257-265. doi:10.1089/sur.2011.007

50. Wick EC, Shore AD, Hirose K, et al. Readmission rates and cost following colorectal surgery. Dis Colon Rectum. 2011;54(12):14751479. doi:10.1097/DCR.0b013e31822ff8f0

51. Trick WE, Scheckler WE, Tokars JI, et al. Modifiable risk factors associated with deep sternal site infection after coronary artery bypass grafting. $J$ Thorac Cardiovasc Surg. 2000;119(1):108-114. doi:10.1016/s0022-5223(00)70224-8

52. Borger MA, Rao V, Weisel RD, et al. Deep sternal wound infection: risk factors and outcomes. Ann Thorac Surg. 1998;65(4):1050-1056. doi:10.1016/s0003-4975(98)00063-0

53. Jencks SF, M V W, Coleman EA. Rehospitalizations among patients in the medicare fee-for-service program. $N$ Engl J Med. 2009;360 (14):1418-1428. doi:10.1056/NEJMsa0803563

54. Kaye KS, Anderson DJ, Sloane R, et al. The effect of surgical site infection on older operative patients. $J$ Am Geriatr Soc. 2009;57 (1):46-54. doi:10.1111/j.1532-5415.2008.02053.x

55. Lu Q, Xie S-Q, Chen S-Y, Chen L-J, Qin Q. Experience of 1166 thyroidectomy without use of prophylactic antibiotic. Biomed Res Int. 2014;2014:758432. doi:10.1155/2014/758432

56. Saeedinia S, Nouri M, Azarhomayoun A, et al. The incidence and risk factors for surgical site infection after clean spinal operations: a prospective cohort study and review of the literature. Surg Neurol Int. 2015;6(1):154. doi:10.4103/2152-7806.166194

57. Gheorghe A, Moran G, Duffy H, Roberts T, Pinkney T, Calvert M. Health utility values associated with surgical site infection: a systematic review. Value Health. 2015;18(8):1126-1137. doi:10.1016/j. jval.2015.08.004

58. World Medical Association. Ethical Principles for Medical Research Involving Human Subjects Version 2013; 64th World Medical Association General, Fortaleza, BrazilAssembly, October 2013. 2013. Available from: https://www.wma.net/policies-post/wmadeclaration-of-helsinki-ethical-principles-for-medical-research-invol ving-human-subjects/. Accessed July 11, 2019.

\section{Dovepress}

antibiotic resistance and the mechanisms of resistance development and diffusion in both hospitals and the community. The manuscript management system is completely online and includes a very quick and fair peerreview system, which is all easy to use. Visit http://www.dovepress.com/ testimonials.php to read real quotes from published authors. 